\title{
PROTAGONISMO DISCENTE EM PROCESSOS DE CONSTITUIÇÃO DE LETRAMENTOS ACADÊMICOS
}

\section{STUDENT'S PROTAGONISM IN PROCESSES OF CONSTRUCTING ACADEMIC LITERACIES}

\author{
Patrícia Forgiarini Firpo \\ Universidade Federal do Pampa, Dom Pedrito, Rio Grande do Sul, Brasil \\ Clara Dornelles \\ Universidade Federal do Pampa, Bagé, Rio Grande do Sul, Brasil
}

\begin{abstract}
Resumo: Apresentamos resultados de uma pesquisa que buscou incentivar estudantes ingressantes na universidade a desenvolver práticas de letramento acadêmico, sob a concepção de letramentos enquanto práticas sociais. Ancoradas nos Novos Estudos do Letramento (STREET, 2014), em especial aqueles que se dedicam aos letramentos acadêmicos (ZAVALA, 2009; LEA, STREET, 1998; FIAD, 2011, 2013; JUCHUM, 2016), desenvolvemos uma pesquisa-ação (TRIPP, 2005) em Linguística Aplicada (MOITA LOPES, 2006) associada à etnografia virtual (HINE, 2000). Planejamos e implementamos um curso em ambiente virtual que visou à construção de uma comunidade colaborativa online a partir da valorização das identidades dos alunos (FIRPO, 2018). Neste artigo, analisamos evidências dos letramentos acadêmicos construídos em textos de autoria dos estudantes publicados no jornal universitário digital produzido por um grupo de alunos veteranos. Os resultados desta pesquisa contribuem para a superação do discurso do deficit de leitura e escrita dos alunos, pois nas produções analisadas, em que escreveram e publicaram textos sobre suas vivências após o ingresso no ensino superior, demonstraram protagonismo discente como agentes de letramentos acadêmicos.
\end{abstract}

Palavras-chave: Letramentos Acadêmicos; Discurso do Déficit; Protagonismo Discente

\begin{abstract}
This paper presents the result of a research that intended to motivate first year university students to develop literacy academic practices, under the conception of literacies as social practices. Relying on New Literacy Studies (STREET, 2014), especially the ones that deal with academic literacies (ZAVALA, 2009; LEA, STREET, 1998; FIAD, 2011, 2013; JUCHUM, 2016), we developed an action-research (TRIPP, 2005) in Applied Linguistics (MOITA LOPES, 2006) associated with virtual ethnography (HINE, 2000). We planned and implemented an online course aiming at constructing a collaborative community solidified on the valorization of students' identities (FIRPO, 2018). We thus analyze the evidence of the academic literacies constructed in texts written by the students and published in the online university journal produced by more experienced students. The results contribute to challenge the deficit discourse about students' reading and writing performances. In the texts analyzed, students wrote and published about their experiences after entering the university, they demonstrated protagonism as agents of academic literacies.
\end{abstract}

Keywords: Academic Literacies; Deficit Discourse; Student's Protagonism 


\section{INTRODUÇÃO}

O acesso ao ensino superior se popularizou e fazer parte do corpo discente de uma universidade não é mais privilégio daqueles indivíduos pertencentes aos grupos mais favorecidos. De acordo com o balanço realizado pela Secretaria de Educação Superior (20032014), em decorrência das políticas públicas ${ }^{1}$ para expansão e interiorização, o perfil dos alunos ingressantes está se alterando substancialmente, num processo de democratização que objetiva transformar uma realidade em que "ir à universidade é opção reservada às elites" (BRASIL, 2014, p. 19).

Ademais, destaca-se como um dos marcos dessa política, o sistema de cotas afirmativas definido pela Lei $\mathrm{n}^{\mathrm{o}}$ 12.711/2012. Até então, cada instituição tinha autonomia para regular suas políticas de ações afirmativas. A partir do momento que se instituiu tal legislação, de forma gradativa, sistema de ingresso no ensino superior passou a ser unificado, de forma a dar equidade de acesso para grupos que historicamente estiveram à margem do ensino superior. No Brasil, as ações afirmativas contemplam $50 \%$ das vagas para estudantes que cursaram todo o ensino médio em escolas públicas. Destas vagas, 50\% são destinadas àqueles cuja renda familiar per capita não ultrapasse 1,5 salários mínimos. Além disso, assegura-se dentre essas reservas de vagas a proporção da população negra, parda e indígena em que a instituição está localizada (BRASIL, 2014).

As instituições públicas de ensino superior começam, então, a receber um número maior de negros, campesinos, indígenas, pessoas com deficiência e de baixa renda. As políticas públicas tornam-se cada vez mais sensíveis para a garantia de acesso, assegurando igualdade de condições a grupos sociais cada vez mais diversos, porém ainda há carência de mais planejamento e de projetos institucionais que visem à permanência destes alunos na universidade.

A exemplo do que ocorre também em outras universidades, na Universidade Federal do Pampa (UNIPAMPA), campo em que se realiza o presente estudo, as práticas pedagógicas não seguem esse mesmo ritmo de expansão. Dessa forma, continua-se ministrando aulas como se a comunidade acadêmica fosse a mesma elitizada e homogênea de outrora. $\mathrm{Na}$ aspiração por um aluno ideal, desvalorizam-se as culturas daqueles alunos que ainda não estão familiarizados com as convenções da academia.

Ocorre, então, para conveniência ou mesmo comodidade de muitos que ainda são contrários às políticas de garantia de acesso ao ensino superior, um novo processo de seleção silencioso, velado e opressor - e, esse sim, garante que somente aqueles que já dominavam as habilidades técnicas exigidas pela universidade permaneçam, excluindo mais uma vez aqueles que não herdaram o capital cultural ${ }^{2}$, os conhecimentos valorizados na academia e legitimados pela elite dominante.

A atribuição das dificuldades em leitura e escrita ao novo perfil dos discentes das instituições do ensino superior tem sido discutida em estudos recentes sobre letramentos acadêmicos (cf. JUCHUM, 2016). Mas a problemática já é conhecida em espaços acadêmicos

\footnotetext{
1 Dentre estes programas de democratização e inclusão destacam-se: Programa Universidade Para Todos (Prouni), Fundo de Financiamento ao Estudante do Ensino Superior (Fies), Sistema de Seleção Unificada (Sisu), Programa de Bolsa Permanência (PBP), Acessibilidade na Educação Superior (Programa Incluir) e Programa Nacional de Assistência Estudantil (Pnaes).

${ }^{2}$ Capital cultural é um conceito desenvolvido pelo sociólogo francês Pierre Bourdieu, em que os indivíduos pertencentes às classes sociais mais favorecidas recebem da família o acesso aos bens culturais considerados de maior prestígio. Essa herança, metaforicamente, vira uma moeda de poder e dominação em que somente uma cultura é valorizada. O reflexo disso na escola é a desvantagem dos alunos que não tiveram acesso à cultura dominante. Para saber mais sobre o conceito ver Bourdieu e Passeron (1992), nas referências deste trabalho.
} 
que, mesmo antes das políticas de expansão, evidenciavam a diversidade das experiências em leitura e escrita dos estudantes universitários (cf. FIAD, 2011). Além disso, esta realidade não é apenas do Brasil. Zavala (2009), ao contextualizar a problemática de seus estudos no Peru, nos remete a uma realidade similar: espera-se que os estudantes ingressem prontos para responder às exigências da academia. Porém, com a massificação do ensino superior, surge uma nova realidade. Se antes fazia parte destes locais uma elite que já estava preparada para essas práticas, ou ainda, cujos usos da língua não estavam tão distantes dos professores, agora novos tipos de alunos ingressam nessas instituições e, muitas vezes, possuem maneiras diferentes de pensar, agir, falar, e essas diferenças acabam entrando em conflito.

Ancoradas nos Novos Estudos do Letramento - NEL (STREET, 2014), em especial aqueles que se dedicam aos letramentos acadêmicos (ZAVALA, 2009; LEA, STREET, 1998; FIAD, 2011, 2013; JUCHUM, 2016), desenvolvemos uma pesquisa-ação (TRIPP, 2005) em Linguística Aplicada (MOITA LOPES, 2006) associada à etnografia virtual (HINE, 2000). Planejamos e implementamos um curso em ambiente virtual que visou à construção de uma comunidade colaborativa online a partir da valorização das identidades dos alunos (FIRPO, 2018). Neste artigo fazemos um recorte dos resultados, para discutir as evidências dos letramentos acadêmicos construídos em textos escritos por alunos ingressantes no ensino superior, publicados em um jornal universitário como culminância do curso citado.

No texto que segue, desenvolvemos nossa reflexão teórica sobre letramentos acadêmicos, apresentamos o contexto, os participantes e os procedimentos metodológicos da pesquisa, para então discutirmos dados que possibilitam ampliar a reflexão acerca do modo como os estudantes protagonizam os processos de letramentos na universidade ${ }^{3}$. Pretendemos, assim, colaborar para a compreensão de como o olhar sensível e a intervenção voltada ao letramento acadêmico podem lançar luzes para elevar a autoestima discente por meio da valorização de suas identidades singulares e, com isso, promover o acolhimento dos estudantes universitários, ao invés de perpetuar um ciclo de exclusão que invisibiliza as vulnerabilidades socioeconômicas, culturais e psicológicas.

\section{A PERSPECTIVA DO LETRAMENTO ACADÊMICO}

Metodologias de ensino inadequadas, avaliações que visam à punição por notas ao invés da análise dos aprendizados processuais, relações hierarquizadas em que o professor exerce o poder sobre os alunos são somente alguns dos exemplos de condutas excludentes que ainda ocorrem na universidade. Todavia, essas atitudes não são levadas em consideração para justificar o porquê de muitos alunos não progredirem e, pelo contrário, culpabiliza-se o próprio aluno pelo seu fracasso.

Sob a mesma ótica de culpabilização do aluno, o recorrente discurso sobre essas pessoas possuírem um deficit de leitura e escrita (JUCHUM, 2016) só faz aumentar o problema. O próprio aluno se convence de que realmente não sabe escrever, como uma deficiência que possui e que dificilmente conseguirá reverter. Este discurso acadêmico acaba "desempoderando os alunos" (ZAVALA, 2009, p. 3, tradução nossa), pois não se leva em consideração que o aluno já está naturalmente cercado de textos (escritos, orais, visuais etc.) em seu dia a dia, dentro e fora da universidade, antes e depois de seu ingresso e, portanto, é letrado, mesmo que ainda não tenha se engajado nas práticas letradas exigidas pela academia

\footnotetext{
${ }^{3}$ Os dados deste artigo fazem parte de pesquisa mais ampla, realizada no âmbito do mestrado profissional em Ensino de Línguas, da Universidade Federal do Pampa, campus Bagé, RS, em que foi desenvolvida, implementada e avaliada uma proposta pedagógica com base na concepção do letramento como prática social. Durante a pesquisa investigamos as potencialidades dos ambientes virtuais na apropriação de práticas de letramentos acadêmicos no processo de construção de uma comunidade colaborativa online por e com alunos ingressantes no ensino superior.
} 
(FIAD, 2011).

Zavala (2009) afirma que, sob a perspectiva dos NEL, surgem pesquisas sobre o letramento acadêmico que criticam a visão de neutralidade da linguagem acadêmica baseada em conceitos de racionalidade. Assume-se, portanto, que é preciso bem mais que habilidades técnicas para resolver problemas de leitura e escrita acadêmica, uma vez que estas estão também relacionadas a aspectos que envolvem identidade e poder.

Conforme Juchum (2016), assumindo um aspecto mais social, os Estudos dos Letramentos Acadêmicos buscam, para superar esse discurso do deficit, contemplar as diversas formas como os indivíduos que fazem parte dos processos de ensino e de aprendizagem, tanto professores como alunos, se engajam com os diferentes textos que permeiam as práticas letradas da universidade. Em sua pesquisa, a autora constrói e desenvolve uma proposta de letramento acadêmico através de uma metodologia de trabalho com projetos. Dentre as suas conclusões, nega o discurso do deficit, superado por meio da valorização da cultura e dos conhecimentos prévios dos alunos, que se engajaram em atividades de leitura e escrita com propósitos sociais (JUCHUM, 2016).

De fato, os modos de falar, de agir e, principalmente, de escrever, na universidade, são muito diferentes daquilo que o aluno pratica em outros contextos sociais (JUCHUM, 2016). Entendemos que tal fenômeno precisa ser considerado para que o aluno possa, gradualmente, ir adquirindo as novas linguagens, compreendendo os novos modos do agir, especialmente no que se refere à escrita. Para a autora, as dificuldades dos estudantes estão relacionadas a problemas de adaptação ao contexto universitário. Nesse sentido, é importante considerar aspectos que envolvem o capital cultural desses estudantes que ingressam na universidade. Assim, acreditamos que não se trata de insuficiência de capacidade de leitura, escrita e oralidade, ou deficit de letramento, mas diferença.

Pesquisas sobre letramentos acadêmicos decorrem da observação das escritas de estudantes de diferentes classes sociais e etnias que, quando entram na universidade, precisam produzir gêneros acadêmicos com os quais não possuem familiaridade e, por consequência, não desempenham o esperado e são mal avaliados pelos professores (FIAD, 2011). Na pesquisa de Fiad (2011, p. 365), a autora afirma que, dentre as práticas da escrita acadêmica com as quais os alunos ainda não tinham muita familiaridade, ressaltam-se "práticas como 'reescrever', 'tratar de temas polêmicos', 'discutir', 'ter espírito crítico', 'trabalhar em equipe"'. Destaca o aprendizado de alguns gêneros acadêmicos como resumo e resenha. Mas, "a consciência de que escreve para um leitor e que é importante levar isso em conta durante sua escrita" (FIAD, 2011, p. 365).demonstrou-se como um dos aspectos mais presentes nas reflexões daqueles alunos pesquisados e mais relevante no processo de aquisição do letramento acadêmico.

Em estudo posterior, Fiad (2013) questiona a crença, já mencionada no presente estudo, de que o aluno deve possuir o letramento valorizado pela academia antes mesmo de seu ingresso. Essa ideia deve ser questionada levando em consideração a multiplicidade de letramentos e considerando os letramentos que os alunos já possuem como ponto de partida para práticas pedagógicas que visem à aprendizagem de novos letramentos, no caso dos letramentos acadêmicos (FIAD, 2013).

Motivados pela problemática da decadência do letramento do aluno, desde a educação básica até o ensino superior, sustentadas por professores que dizem que os alunos não sabem mais escrever, Lea e Street (1998) centram suas pesquisas através de uma abordagem mais ampla que considera a complexidade das práticas de escrita, contrapondo-se àquelas que defendem o deficit do aluno, baseadas em habilidades individuais. Defendem, por sua vez, que os estudos sobre as escritas dos alunos apresentam-se em três modelos: o modelo das habilidades, o modelo da socialização acadêmica e o modelo dos letramentos acadêmicos. 
No modelo das habilidades considera-se que o aluno não sabe escrever, sendo este um problema ou deficit que deve ser consertado. No modelo de socialização acadêmica, o professor deve ensinar para o aluno as formas de agir, falar e escrever da universidade, mas não leva em consideração os letramentos que o aluno já possui, como se sua bagagem sociocultural pudesse ser até um problema para a aprendizagem dos novos letramentos. $\mathrm{Na}$ abordagem dos letramentos acadêmicos, as práticas sociais de leitura e escrita são consideradas em sua complexidade socio histórica e discursiva, que não apaga as relações de poder e de identidades que as permeiam.

Os autores ressaltam os conflitos ideológicos e afetivos decorrentes das formas de escrever na universidade, impessoais e passivas, em que o aluno perde a sua identidade, pois, dadas as situações e o contexto, nos modelos das habilidades e no de socialização acadêmica é exigido que os estudantes utilizem repertórios linguísticos muito diferentes das formas que lhes eram usuais. Para os autores, a visão do modelo dos letramentos acadêmicos, centrada no envolvimento do aluno com a escrita e que leva em consideração identidades e significados sociais é a que mais se aproxima dos NEL. Em suma, para que o ensino atenda ao modelo de letramentos acadêmicos proposto por esses autores, é preciso repensar as práticas pedagógicas, considerando as pessoas envolvidas e os contextos locais e situados.

A partir dessa ressignificação pedagógica, pudemos pensar em uma prática que considera os conhecimentos e as identidades dos alunos, procurando valorizar suas vozes, encorajando-os a buscar sua emancipação e participação na comunidade acadêmica, pois, segundo Britto (2007), sob uma concepção política de letramento, é preciso mais do que a apropriação de conhecimentos de leitura e escrita como norma ou tecnologia; é preciso tomar a leitura e a escrita como meios de participação e modificação da sociedade.

\section{METODOLOGIA}

Este trabalho consiste em uma pesquisa-ação qualitativa em Linguística Aplicada (LA), considerando os "novos modos de teorizar e fazer LA" (MOITA LOPES, 2006, p. 22). Devido à relevância dada ao social e situado no campo aplicado dos estudos da linguagem, desenvolvemos esta pesquisa com o aporte dessa nova LA que, por ser considerada "indisciplinar" (MOITA LOPES, 2006), possibilita associação também à etnografia virtual que, por sua vez, é baseada em perspectivas etnográficas mais recentes e difere da etnografia tradicional, principalmente no que se refere ao seu campo de pesquisa, a internet (HINE, 2000).

Os textos que analisamos neste artigo são produções finais do curso que desenvolvemos a partir de uma proposta pedagógica com base na concepção do letramento como prática social. Essa proposta foi implementada, na forma do curso online, que teve o Moodle como Ambiente Virtual de Aprendizagem (AVA). No curso, intitulado "\#aprovados: Práticas de letramentos acadêmicos e vivências universitárias"4, as tarefas pedagógicas objetivavam fomentar o engajamento ${ }^{5}$ dos alunos ingressantes em cursos de graduação da UNIPAMPA, campus Dom Pedrito/ RS, em atividades que os envolvessem em práticas colaborativas de letramentos acadêmicos. Para alcançar a meta, eram objetivos específicos de aprendizagem:

\footnotetext{
${ }^{4}$ O curso iniciou no dia 26 de fevereiro de 2018, antes do início do período letivo regular, e culminou com entrega da revisão da versão final de produção escrita de autoria dos estudantes participantes do curso, em 24 de abril de 2018.

${ }^{5}$ Discussões teóricas referentes ao conceito de "engajamento" não serão abordadas nesta pesquisa. Utilizo o termo como participação dos alunos nas atividades.
} 
a) Conhecer a universidade, a cidade, o campus e os cursos de graduação;

b) Reconhecer e refletir sobre aspectos que envolvem leitura e escrita na universidade;

c) Escrever e publicar um texto sobre sua experiência como aluno ingressante.

Durante o curso "\#aprovados" foram abordadas funções e características de gêneros acadêmicos como resumo, resenha, projeto de pesquisa, entre outros, devido à reconhecida importância na academia. Entretanto, para a atividade final de escrita, que seria publicada, os alunos poderiam escolher qual gênero discursivo utilizariam para compartilhar suas vivências. Os gêneros escolhidos foram relato de experiência (em sua maioria) e poema, todos adequados ao meio de circulação (jornal universitário), ao conteúdo temático (vivência de alunos ingressantes no curso/na universidade) e ao público de leitores (alunos ingressantes no ensino superior). Tais escolhas fomentaram práticas de leitura e escrita como meio de engajamento/participação estudantil, a partir da valorização de outros modos de escrever na universidade. Entendemos que para que o aluno possa construir seus letramentos enquanto sujeito universitário, é fundamental que reflita sobre as novas identidades em jogo no espaço acadêmico. Ao escrever sobre suas experiências, ainda que não em um gênero acadêmico prototípico, os estudantes construíram um projeto de dizer que possibilitou ser autor na esfera acadêmica.

Assim, os textos produzidos pelos alunos ao longo da proposta pedagógica (comentários e postagens no AVA; relatos de experiência e poemas para publicação final) foram o material etnográfico de uma análise que leva em consideração o contexto em que são escritos/produzidos para procurar compreender os sentidos constituídos. O campo de investigação foi a sala de aula virtual (AVA - Moodle) e o objeto de estudo são as relações sociais manifestadas pela escrita.

A proposta pedagógica culminou com a entrega da versão final de produção escrita de autoria dos estudantes participantes do curso "\#aprovados", as quais foram submetidas à publicação no Jornal Universitário do Pampa (Junipampa) ${ }^{6}$. Analisamos neste artigo os textos das três (03) alunas que tiveram maior participação e engajamento para realização das atividades do curso. O critério para avaliar a participação, e portanto realizar este recorte, foi o engajamento para a realização das atividades propostas (individuais e colaborativas) registrado em rubricas de avaliação da atuação discente ${ }^{7}$. Os dados são apresentados a partir do prints de excertos das produções publicadas no site do jornal. A partir dos excertos, analisamos as percepções dos alunos sobre o que é ser um aluno ingressante na universidade. Entendemos que esses textos expressam o resultado do processo de constituição de letramentos acadêmicos construídos durante o curso, sobretudo porque a partir da valorização das suas percepções, os alunos puderam refletir sobre suas novas identidades e possíveis interlocutores no espaço acadêmico.

\footnotetext{
${ }^{6}$ O Junipampa é um jornal digital produzido por estudantes, egressos, técnicos e docentes da Universidade Federal do Pampa (UNIPAMPA), de modo colaborativo. Como ação de extensão, integra produções também da comunidade não acadêmica. Os estudantes costumam dizer que seu interesse pelo Junipampa está associado ao fato de que, nesse espaço, se sentem "livres", "autores". É um espaço onde podem dizer o que na maioria das vezes não se pode dizer no contexto de ensino universitário. Para saber mais, sugerimos a leitura de Guimarães e Dornelles (2016), e a visitação do site do jornal: junipampa.info

${ }^{7}$ Para cada tarefa do curso foram definidos critérios de participação (como acessar o material, participar das discussões, realizar tarefas extraclasse, individuais ou em grupos) e escalas de participação para cada critério (alcançou, alcançou parcialmente ou não alcançou). A partir daí definimos as alunas mais engajadas, aquelas que alcançaram mais plenamente os objetivos das tarefas.
} 
Os participantes da pesquisa foram vinte e três (23) alunos, os quais fizeram a inscrição no curso "\#aprovados", e aceitaram participar da nossa pesquisa9. Do total de alunos inscritos, dez (10) já residiam em Dom Pedrito, doze (12) em outras cidades do estado e uma (01) aluna residia em Mato Grosso. Os alunos eram dos seguintes cursos de graduação: Zootecnia, Tecnologia do Agronegócio, Licenciatura em Ciências da Natureza e Licenciatura em Educação do campo; e entraram pelas cotas das Ações Afirmativas. A maioria, dezesseis (16) alunos, tinha até trinta anos, cinco (05) mais de quarenta anos, e um (01) entre trinta e um e quarenta anos. Grande parte dos alunos relatou nunca ter participado de algum curso, minicurso, oficina, treinamento etc., na modalidade de ensino a distância.

Na próxima seção, apresentamos a análise e discussão dos dados, adicionando também informações sobre os alunos consideradas relevantes para a compreensão dos letramentos constituídos em seus textos.

\section{ANÁLISE E DISCUSSÃO DE DADOS}

Para buscar evidências dos letramentos acadêmicos construídos a partir da participação discente ao longo da proposta pedagógica, lançamos nosso olhar para a última atividade do curso "\#aprovados", que resultou na escrita de textos, em que os alunos socializam suas percepções sobre o que é ser um aluno ingressante. Esses textos representam o resultado do processo de constituição de letramentos acadêmicos durante o curso, finalizado com a submissão dos textos para publicação no jornal universitário.

O primeiro texto analisado é um poema, escrito por Mara ${ }^{10}$, intitulado "Superação". O texto dessa aluna, oriunda de uma comunidade campesina, que vivia suas primeiras experiências universitárias no curso de Licenciatura em Educação do Campo, evidencia, em um primeiro momento, o distanciamento da universidade em relação à sua vida, algo desconhecido, que causava medo: "A universidade parecia algo impossível", "um monstro assustador".

Aos poucos, em sua escrita, a aluna vai mostrando letramentos acadêmicos constituídos, projetando sua identidade como universitária "segui em frente e a realidade me acordou para um autoconhecimento". Ao final, a discente protagoniza reflexões significativas referentes à tomada de consciência sobre a importância de uma universidade plural e colabora com seus leitores, por meio de uma escrita permeada de emoções e de incentivo para a superação, como o título já anuncia, do medo de ingressar na universidade: "Não importa a idade, cultura e cor, somos capazes [...]", "Nós estamos aqui para fazer a diferença na sociedade[...]". Como incentivo para seus leitores, Mara escreveu: "O conhecimento precisa transpor esse medo, porque para Unipampa cada aluno é um ser muito importante [...]”.

\footnotetext{
${ }^{8}$ Desse universo de alunos, quinze (15) frequentaram as aulas, sendo que doze (12) obtiveram participação e aproveitamento suficiente para aprovação e três (03) não concluíram o curso, ou seja, não participaram de atividades suficientes para alcançar aprovação no curso. Os demais, oito (08) alunos, evadiram logo nas primeiras semanas do curso.

${ }_{9}^{9}$ Assinaram termo de consentimento livre e esclarecido.

${ }^{10}$ Utilizamos pseudônimos para manter o anonimato dos participantes.
} 


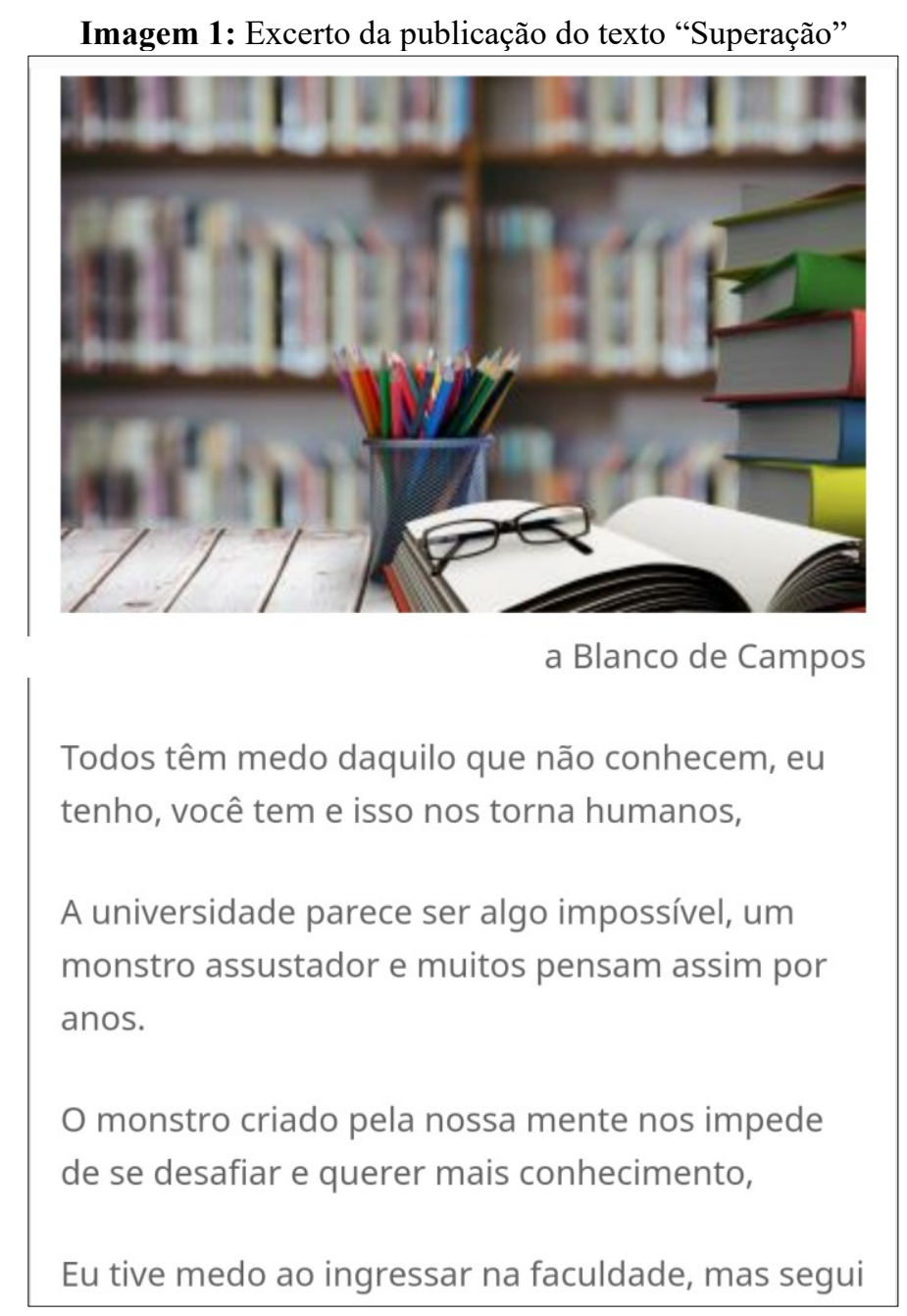

Fonte: Jornal Universitário do Pampa (2018).

O texto demonstra as diferentes perspectivas que a aluna tinha sobre o ensino superior, primeiro antes de ser universitária e depois após passar a ter suas primeiras experiências na graduação. A falta de familiaridade e, por consequência, o medo que sentia daquele contexto desconhecido, fica evidente na escrita da aluna.

Mara enfatiza a superação de uma das barreiras impostas a esse grupo de pessoas, o difícil acesso à universidade. A aluna, assim como os demais participantes dessa pesquisa, faz parte do novo perfil de discentes do ensino superior, que foi alterado por consequência das políticas públicas para expansão e democratização do ensino superior (BRASIL, 2014).

A imagem, escolhida pela aluna para representar seu texto, traz elementos de um cotidiano de estudos, que fazem parte da vida de estudante, dando indícios da relação do texto escrito com a identidade assumida pela aluna enquanto universitária. Convida seus leitores, a superarem seus medos e passem a tomar espaço que é de direito, uma universidade em que as pessoas são valorizadas. A aluna viveu essa mudança na sua vida e convida aos leitores para que tomem coragem e sigam seu exemplo.

O segundo texto, "Força de vontade", escrito por Leonora, traz para representar sua escrita uma imagem que representa a sua luta contra o câncer. O ingresso na universidade é marcado como oportunidade para uma nova vida e a palavra superação também é trazida em destaque.

Desde a introdução, a estudante autora do texto a seguir demonstrou ter adquirido um conhecimento que, segundo Fiad (2011), é um dos mais relevantes na constituição dos letramentos acadêmicos, que é a consciência de que se escreve para um leitor: "Escrevo este 
relato de experiência para compartilhar com vocês como foi e está sendo a minha vida acadêmica ao ingressar na Unipampa". Neste caso, a consciência de uma nova identidade que assume, de estudante universitária. A aluna também mencionou em seu texto o medo que sentiu ao ingressar no ensino superior: "Confesso que fiquei com um pouco de medo, se seriam muito difíceis as aulas, mas a cada aula que passa, está aumentando cada vez mais a curiosidade sobre cada tema proposto". Assim, ela começa a ter "curiosidade" sobre os temas acadêmicos, que poderá gerar inquietações e indagações, fundamentos da produção do conhecimento científico.

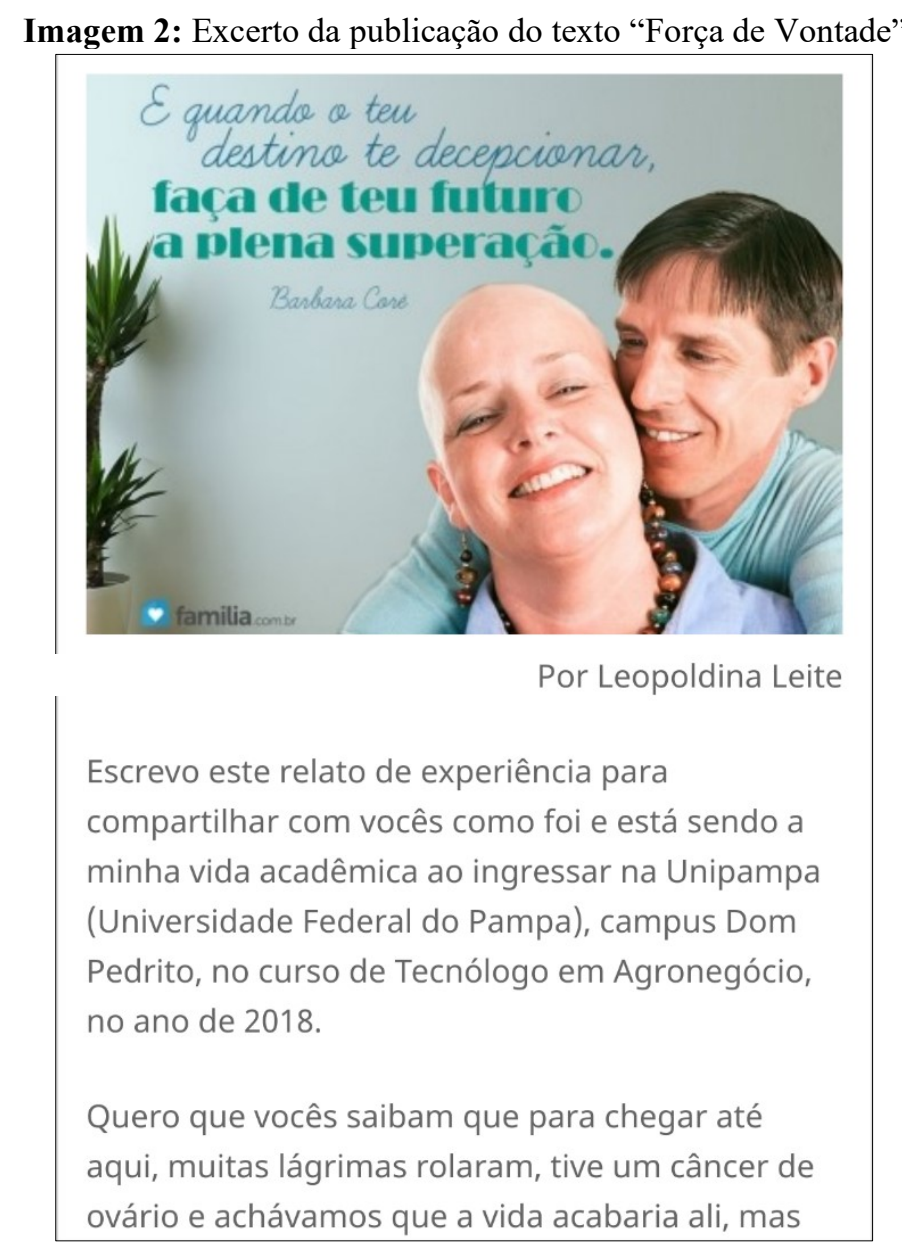

Fonte: Jornal Universitário do Pampa (2018).

Fazendo uma referência ao curso "\#aprovados", ela escreveu "Uma das minhas maiores dificuldades está sendo a adaptação à linguagem acadêmica. Sempre tive dificuldade em interpretar textos e escrever". Em sua conclusão, "mas agora estou aprendendo muito com o curso de letramento que foi oferecido pela universidade [...]", a aluna demonstra a relevância para os alunos da oferta institucional de cursos como o que concretizamos nesta pesquisa. Por fim, finda seu texto incentivando seus leitores: "Aos novos ingressantes, que pensam em entrar em uma vida acadêmica, tenham muita força de vontade e foco no futuro, pois com certeza se tornarão excelentes profissionais e vencedores", e, desse modo, demonstrando práticas de letramentos ao utilizar a escrita para colaborar com outras pessoas, participando e interferindo na comunidade (BRITTO, 2007).

O terceiro texto analisado é intitulado "O INÍCIO DE UMA NOVA ETAPA" e foi escrito por Tatiana que, aos 17 anos estava vivendo pela primeira vez a experiência de deixar a casa dos pais para estudar. A aluna inicia seu texto: "Estou ingressando na Universidade 
Federal do Pampa, especificamente no campus de Dom Pedrito, para cursar Tecnólogo em Agronegócio". Assim, continua: "Neste ano de 2018, e, com o objetivo de ajudar a todos que estejam interessados em ingressar futuramente ou estejam ingressando na UNIPAMPA, vou compartilhar minha experiência". Nesse texto também fica evidenciada a apreensão de que a escrita tem função e leitores específicos.

O medo da mudança também está marcado no texto ao falar sobre os caminhos que poderia percorrer após terminar o ensino médio: "Bem, eu tinha várias ideias, como trabalhar, [...] ou tentar uma faculdade, mas acredite nenhuma dessas ideias envolvia eu ir para longe dos meus pais". A dificuldade de deixar a casa dos pais foi um desafio para ela, que diz: "Sempre fui dentre meus irmãos a mais apegada".

Tatiana escolheu para representar seu texto escrito uma fotografia do "trote", para compartilhar com seus leitores um momento que, para ela, foi significativo ao entrar na universidade: “[...] não poderia deixar de contar minha experiência com o 'trote' ou, em outras palavras, a integração com os veteranos". Na sequência: "Posso dizer que é uma experiência única onde você faz amizades se diverte e conhece pessoas que poderão te dar uma base nessa etapa inicial". E ressaltou a importância dos alunos mais experientes na adaptação à universidade.

Concluiu, assim, seu relato incentivando seus leitores: “[...] posso dizer que de certa forma você terá uma família na sua caminhada acadêmica, assim como eu tenho a minha e estou me adaptando a uma nova cidade, [...]". Por fim: "Espero que você, assim como eu, leve essas experiências para o lado da aprendizagem". A aluna conversa com o leitor e incentiva à autonomia na busca pelo conhecimento.

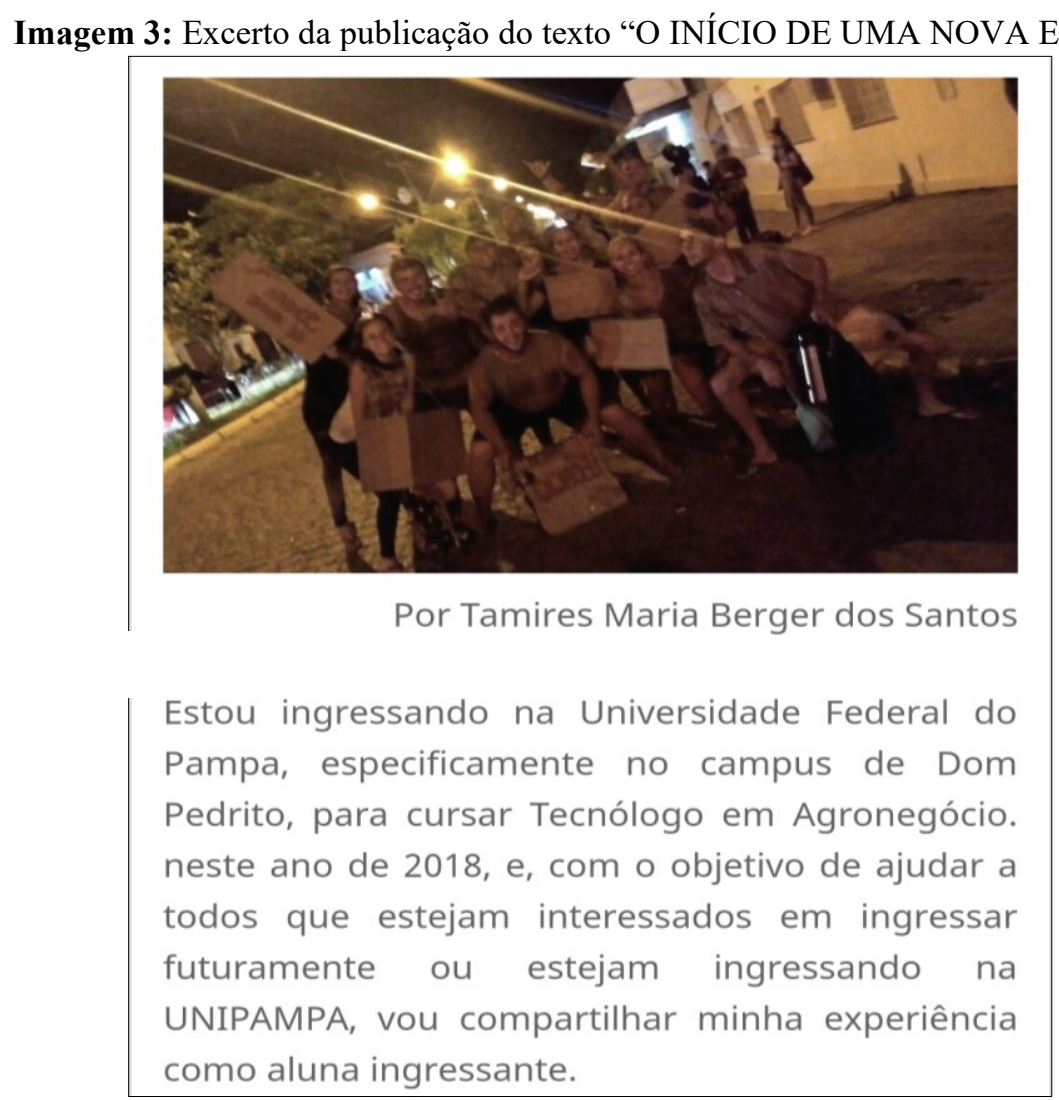

Fonte: Jornal Universitário do Pampa (2018).

Analisando os textos sob a perspectiva das alunas que os escreveram, destacamos três importantes processos de constituição de letramentos acadêmicos enquanto práticas 
sociais. Em primeiro lugar, a proposta pedagógica que fomentou as produções escritas aqui analisadas possibilitou que as alunas escrevessem tendo como ponto de partida os conhecimentos que possuíam (suas expectativas, representações e medos), valorizando suas culturas, experiências e possibilitando a aquisição de novos letramentos e novos modos de dizer na universidade (JUCHUM, 2016). Neste ponto, entendemos que a construção de novos modos de dizer na esfera acadêmica se deu desde a escolha do gênero discursivo para a produção final à mobilização da temática proposta, que abriu espaço para a expressão de diferentes identidades da esfera pessoal, mas também para a busca de algo em comum na esfera acadêmica, emergindo desse movimento uma ideia de comunidade em que "novatos" dialogam com os estudantes mais experientes.

O segundo processo diz respeito a questões de ideologia e poder (ZAVALA, 2009) que permeiam a escrita na academia e a importância de oportunizar espaços, como o Junipampa e o próprio curso "\#aprovados", em que as autoras, assumindo suas identidades enquanto universitárias, participam e intervêm na sociedade por meio de textos, protagonizando práticas de letramentos de relevância para comunidade acadêmica.

$\mathrm{E}$, terceiro, observamos que essas alunas atestam o sentido que as práticas de leitura e escrita passam a ter após se tornarem autoras. A consciência de que se escreve para um leitor e a adequação ao meio de circulação do texto demonstra o nível de letramento que as alunas alcançaram já nesta etapa inicial de suas vidas acadêmicas, pois, conforme Fiad (2011), considerar esse leitor no processo de escrita é um dos conhecimentos mais importantes na constituição de letramentos acadêmicos. Embora esse processo de consciência do projeto discursivo de um gênero possa ser iniciado na escola, esta não é a realidade da maior parte dos estudantes do nosso contexto de pesquisa. Assim, quando as alunas autoras fazem uso de gêneros do discurso que não são prototípicos na academia, mas que possibilitam explorar o conteúdo temático (vivências universitárias) de maneira a construir interlocução com outros (novos) sujeitos universitários, temos letramentos acadêmicos em construção.

As alunas socializaram seus medos, suas percepções sobre a universidade e escreveram textos que prestaram/prestarão auxílio para outros alunos, demonstrando o empenho em colaborar com outras pessoas, para além do tradicional conhecimento disciplinar. Com a produção escrita ao final do curso "\#aprovados", colocaram em prática conhecimentos adquiridos com e pelo grupo, ao produzirem e socializarem textos que circularam no contexto acadêmico, tornando-as importantes agentes de letramentos acadêmicos. As produções das estudantes não escamotearam a heterogeneidade e vulnerabilidades, sobretudo socioculturais e psicológicas, enfrentadas pelo coletivo estudantil.

\section{CONSIDERAÇÕES FINAIS}

A produção final das alunas, analisada neste artigo, sugere que, ao atribuir sentido para suas escritas, o processo de adequação da linguagem informal, com que até então estavam mais familiarizadas e utilizaram em grande parte das interações escritas nos fóruns durante o curso "\#aprovados", para um estilo de linguagem mais formal, mais aproximada da linguagem acadêmica, pode ocorrer de forma gradual.

Mas, para além dos aspectos que envolvem leitura, escrita e atribuição de sentidos esperados pela universidade, durante as atividades no curso "\#aprovados", os alunos foram protagonistas da construção de conhecimentos do grupo por meio da colaboração, da reflexão, da expressão de pontos de vista e de suas percepções sobre a universidade. Ao afirmar isso, trazemos as palavras de Britto (2007, p. 24): "muito mais que o domínio de uma norma ou de uma tecnologia, saber ler e escrever implica dispor do conhecimento elaborado e poder usá-lo para participar e intervir na sociedade". 
Verificamos que os alunos vivenciaram práticas de letramentos acadêmicos que se configuraram em processos de aprendizagens e que envolveram principalmente a constituição de suas identidades enquanto universitários, as primeiras descobertas sobre características locais da cidade e do campus onde passarão a conviver e os usos de leitura e escrita no contexto universitário.

Norteadas pela concepção de letramentos enquanto práticas sociais, esperamos contribuir para a desconstrução do discurso do deficit de leitura e escrita dos alunos, através de pedagogias que valorizem seus letramentos e seus conhecimentos prévios ao ingresso na universidade, utilizando-os como ponto de partida para os processos de constituição de letramentos.

\section{Referências}

BOURDIEU, P; PASSERON, J. A Reprodução: Elementos para uma teoria do sistema de ensino. $3^{\mathrm{a}}$ ed. Tradução de Reynaldo Bairão. Rio de Janeiro: Livraria Francisco Alves Editora S.A., 1992.

BRASIL. MINISTÉRIO DA EDUCAÇÃO. A democratização e expansão da educação superior no país 2003 - 2014. Disponível em: http://portal.mec.gov.br/index.php?option=com docman\&view $=$ download\&alias $=16762$ balanco-social-sesu-2003-2014\&Itemid=30192 . Acesso em: 12 out. 2017.

BRITTO, L. P. L. Escola, ensino de língua, letramento e conhecimento. Calidoscópio, Vale dos Sinos. Vol. 5, n. 1, p. 24-30, jan/abr 2007.

FIAD, R. S. A escrita na universidade. Revista da ABRALIN, [S.L]. v. Eletrônico, n. Especial, p. 357-369. 2011.

FIAD, R. S. Reescrita, dialogismo e etnografia. Linguagem em (Dis)curso, Tubarão, SC, v. 13, n. 3, p. 463-480, set./dez. 2013.

FIAD. R. S; MIRANDA, F. D. S. Letramentos digitais e acadêmicos em contexto universitário: investigando práticas letradas em um curso de letras de uma universidade pública. Revista Colineares, [S.L]. n. 1, v. 1, jan/jun 2014.

FIRPO, P. Práticas de letramentos acadêmicos incentivadas por atividades pedagógicas em ambientes virtuais de 2018. Dissertação (Mestrado Profissional em Ensino de Línguas) - Universidade Federal do Pampa, Bagé.

GUIMARÃES, F. T. B.; DORNELLES, C. O processo de construção de um webjornal laboratório: a reescrita colaborativa em foco.. In: GONÇALVES, A. V.; BUIN, E.; CONCEIÇÃO, R. I. S. (Org.). Ensino de língua portuguesa para a contemporaneidade: escrita, leitura e formação de professores. Campinas: Pontes Editora, 2016, v. , p. 215-251.

HINE, C. Virtual Ethnography. London: SAGE Publications, 2000.

JUCHUM, M. Letramentos acadêmicos: projetos de trabalho na universidade. 2016. Tese (Doutorado em Letras) - Universidade Federal do Rio Grande do Sul, Porto Alegre. 
LEA, M. R; STREET, B. V. Student writing in higher education: an academic literacies approach. Studies in Higher Education, [S.L]. Jun 98, Vol. 23 Issue 2, p 157, 16 p.

MOITA LOPES, L.P. (org.). Por uma Lingüistica Aplicada INdisciplinar. São Paulo: Parábola Editorial, 2006.

SANTOS, T. M. B. dos. O INÍCIO DE UMA NOVA ETAPA. Jornal Universitário do Pampa, 2018. Disponível em: http://junipampa.info/cultura/o-inicio-de-uma-nova-etapa/\#.WnMBZNKjIU . Acesso em: 10 maio 2018.

STREET, B. V. Letramentos sociais: abordagens críticas do letramento no desenvolvimento, na etnografia e na educação. Tradução de Marcos Bagno. São Paulo: Parábola Editorial, 2014.

TRIPP, D. Pesquisa-ação: uma introdução metodológica. Educação e Pesquisa, São Paulo, v. 31, n. 3, p. 443-466, set./dez. 2005.

UNIVERSIDADE FEDERAL DO PAMPA. Moodle: Cursos Presenciais. Curso \#aprovados: Práticas de letramentos acadêmicos e vivências universitárias. 2018. Disponível em: https://moodle.unipampa.edu.br/moodle/course/view.php?id=7087. Acesso em: 10 de maio 2018.

ZAVALA, V. “¿Quién está diciendo eso?: literacidad académica, identidad y poder en la educación superior". In: KALMAN, Judith. STREET, Brian (org). Lectura, Escritura y Matemáticas como prácticas sociales: Diálogos desde los Estudios Latinoamericanos sobre Cultura Escrita. México: Siglo XXI, CREFAL (Centro de Cooperación Regional para la Educación de Adultos en América Latina y el Caribe), 2009. Disponível em: https://s3.amazonaws.com/academia.edu.documents/38129081/texto Paula.pdf?AWSAccess KeyId=AKIAIWOWYYGZ2Y53UL3A\&Expires $=1510096249 \&$ Signature $=$ W0FXeQdGR7rx VrcmJVGV2E2XnRE\%3D\&responsecontentdisposition=inline $\% 3 \mathrm{~B} \% 20$ filename $\% 3 \mathrm{DQUIE}$ N_ESTA_DICIENDO_ESO_LITERACIDAD_ACA.pdf. Acesso em: 04 set. 2017.

Patrícia Forgiarini Firpo pf.forgiarini@gmail.com

Clara Dornelles claradornelles@gmail.com

Recebido em: 17 de Julho de 2019 Aceito em: 25 de Agosto de 2019

Publicado em: Setembro de 2019 